\title{
Social Capital and Public Goods ${ }^{1}$
}

\author{
Tammy Leonard, ${ }^{1 *}$ Rachel T. A. Croson ${ }^{1}$ and Angela C. M. de Oliveira ${ }^{2}$ \\ ${ }^{1}$ University of Texas at Dallas \\ ${ }^{2}$ University of Massachusetts Amherst
}

This Draft:

February 3, 2010

Please do not cite or circulate without the authors' permission.

Keywords: Poverty, trust, social network, social capital

JEL Codes: H41, D71, 018

\begin{abstract}
Previous literature suggests positive relationships between social capital, pro-social behavior and subsequent economic development. We analyze the relationship between social networks and trust (two measures of social capital) and self-reported charitable contributions of time and/or money (pro-social behavior) using data collected from two ethnically distinct, low-income neighborhoods. We find that large social networks are positively related to charitable contributions, but that the effects of trust are less robust. We also find that social networks that are more geographically dispersed tend to be larger. Our results indicate that the social capital in a neighborhood is more important than ethnicity, ethnic diversity, or other demographic information in understanding public goods contributions.
\end{abstract}

\footnotetext{
${ }^{1}$ Acknowledgements: We would like to thank Cathleen Johnson, Catherine Eckel, Wayra Rodriguez, Natalia Candelo, and the CBEES staff for assistance with the design and implementation of this project. We would also like to thank the John D. and Catehrine T. MacArthur Foundation and National Science Foundation (SES\#0752855) for financial support.
} 


\section{Social Capital and Public Goods}

Nobel Peace Prize winner Dr. Muhammad Yunus compared the poor to a bonsai tree. There is nothing inherently wrong with the seed, but a lack of adequate soil keeps the tree small and prevents it from reaching great heights (Yunus, 2008). However, unlike the bonsai tree, it is difficult to prescribe a recipe that will allow a poor person to advance beyond poverty. Even if such a recipe existed, it is not clear that the same recipe would work in different contexts. In this paper we assert that the provision of local public goods are one means of increasing economic opportunities for residents of lowincome communities, and we study how the voluntary provision of local public goods might be improved. We do this by examining the relationship between social capital and local public good contributions among the poor.

A growing literature examines observational measures of these constructs and finds a relationship between social capital, local collaborative behavior and economic development (e.g. Olken 2006; Quillian and Redd 2006; Temple 1998; Sampson et al, 1997; Helliwell \& Putnam, 1995). Others use experimental economics techniques to study the determinants of pro-social behavior (see e.g. Camerer 2003, chapter 2; Frey and Stutzer 2007, chapters 3-5 for reviews). Both of these literatures suggest that pro-social behavior will foster a nurturing environment for economic advancement. We contribute to this literature by analyzing measures of social capital and self-reported voluntary contributions by residents of two low-income, minority neighborhoods. Our research advances the existing literature by studying the determinants of pro-social behavior for a group of people (the poor) for which increased pro-social behavior has the potential to 
yield large benefits and in the environment in which the social relationships exist naturally—residential neighborhoods.

We employ survey data to examine the relationships between measures of social capital and self-reported voluntary contributions of time or money to local charitable organizations. Thus, we do not analyze the relationship between pro-social behavior and economic development directly, as has been done in the previous literature. Rather, we focus on the link between social capital and contributions to the public good. This is a possible path-way through which social capital might influence economic development.

We examine residents of two different low-income residential neighborhoods. We ask which features of social interactions might be leveraged to increase public good provision in the neighborhoods and test the contextual nature of these relationships. We find two social capital results that are robust across neighborhoods. First, a larger social network is positively related to the propensity for making neighborhood contributions. Second, network structures that are more geographically dispersed are indicative of larger social networks. These results indicate that social capital is an important factor in understanding local neighborhood giving.

\section{Social Capital}

Social capital was popularized among economists most recently by the seminal work of Putnam (1993) and has since been associated with economic growth and other positive development outcomes (e.g. Beugelsdij \& Van Shaik, 2001; Rodrik, 1999; Temple \& Johnson, 1998; and Adelman \& Morris, 1967). A variety of definitions exist, but social capital may be concisely described as features of social organization, such as social networks and trust (Putnam, 1995). Empirically, social capital has been 
characterized by trusting responses to the World Values Survey trust question:

"Generally speaking, would you say that most people can be trusted, or that you can't be too careful in dealing with people?" Several studies have found that higher percentages of trusting responses to this question correlate positively with GDP growth (Whiteley, 2000; Knack and Keefer, 1997; Rodrik, 1999; and Zak and Knack, 2001).

However, the relationship between a given level of social capital, the context in which it exists, and its economic impact is not always straightforward. Grootaert (1999) found that high income households benefit more from human capital than social capital, but the opposite is true of low-income households. For example, the impact of social capital can vary greatly depending on the other resources (such as wealth, education, or institutions) available as substitutes (Rodrick, 1999; Knack, 1999). This leads to varying effects of social capital across social and economic levels.

Perhaps most lacking from the existing social capital literature is an understanding of the mechanism(s) through which social capital works. Why do countries whose citizens report being more trusting of others have higher GDP growth? Does trust increase the ease of market transactions, thus facilitating growth; or do people trust more because the institutions in these countries function more effectively; or is their some other explanation? Our data will distinguish between two types of social capitaltrust and social networks - in an attempt to move towards an answer to these questions.

\section{Trust}

While trust has the potential to lower transaction costs because it reduces the need for monitoring, the WVS trust question which asks whether people in general can be trusted (hereafter referred to as the "general WVS trust question") has not been a good 
predictor of trusting behavior in experimental trust games (Glaeser et al. 2000). ${ }^{2}$ This suggests that the correlation between the general WVS trust question and per capita GDP, is not a result of greater trusting behavior (lower monitoring costs) in economic exchange. Anderson et al. (2004) proposes another mechanism. They find that the general WVS trust question does have predictive power in estimating giving in a public goods experiment. Thus, trust might increase economic development through its impact on public good provision.

In our study we will address this question by analyzing the relationship between trust and self-reported contributions towards local public goods for individuals in lowincome minority communities. Thus we test the relationship between trust and public good contributions for subjects who trust (or don't trust) individuals within their own community and who give (or don't give) to real public goods. Additionally, the trust question which we utilize is more specific than the general WVS trust question used by the previous author. The question which we use asks whether specific groups of other people can or cannot be trusted.

Our data on trust will indicate if the results found by Anderson et al. (2004) are observed in non-student samples who participate in real-world public good contribution decisions. We believe that undergraduates alone are not a sufficient subject pool for understanding the implications of social capital. Social capital is a resource utilized differently by the rich and the poor and perhaps across other demographic features (Grootaert, 1999). Additionally, we combine the study of trust with the study of social networks.

\footnotetext{
${ }^{2}$ The WVS trust question studied by Glaeser et al. 2000 and Anderson et al. 2004 is "Generally speaking, would you say that most people can be trusted, or that you can't be too careful in dealing with people?".
} 


\section{Social Networks}

While previous empirical studies have examined trust as a measure of social capital, our social capital variables also include measures of social networks. We believe that studying social networks may provide policy insights which are more easily implemented than the policy insights gained from studying trust alone. We thus make a unique contribution to the existing literature by providing a measure of social networks and examining its relationship with voluntary provision. It is difficult to imagine policy prescription which might alter an individual's level of trust directly; but policy can impact the ease of network formation. For example, well-maintained public areas, safe well-lit parks, community festivals and events, and schools whose administrators actively engage the community encourage social network formation. Also, municipal districting can be structured so as to promote pedestrian activity and community gathering places.

We examine two characteristics of social networks that might impact the voluntary provision of public goods in different ways: network size and network structure. The size of the social network is an indicator of the social connectedness of an individual. Individuals with lots of contacts are more likely to be socially engaged, and be able to rely on others as a safety net during times of adversity. However, not all networks of a given size are equal; network structure is also important. "Tight-knit" networks in which all members know each other are referred to as having a closed network structure; while more diverse social networks in which many members do not know each other have an open network structure. We measure the degree of network closure by asking if family members and friends in one's social network know each other. If the answer is yes, the social network structure is characterized as closed. Since 
we are examining the voluntary provision of public goods among neighborhood residents we are also interested in the geographic dispersion of social networks. We measure the geographic concentration of social networks by asking individuals if their network is primarily composed of individuals who reside in the neighborhood or outside of the neighborhood.

\section{Hypothesis}

We explore the relationship between multiple measures of social capital (trust and social networks) and voluntary provision of public goods via self-reported contributions of time and money. In addition to demonstrating these relationships, we compare the relationships across two different neighborhoods which vary in their ethnic and cultural composition.

We expect a positive relationship between trust and voluntary community contributions, in a manner similar to the relationship Anderson et al. (2004) found between trust and experimental public good contributions. However, we also expect social networks to play a role in explaining community contributions. Others have asserted that within the contexts of local neighborhood communities, social networks are likely to be related to voluntary contribution behavior (Miguel et al, 2003; DiPasquale \& Glaeser, 1999; Rose, 1999; Sampson et al, 1997); but none have tested this relationship explicitly.

Other authors have attempted to answer the question of why people contribute/volunteer. For example, McAdams and Paulsen (1993) and Musick et al (2000) point out that often individuals decide to contribute/volunteer because it is "an expression of identity, a feeling of being linked to those who will benefit from one's 
labor" (Musick et al, 2000). This captures the idea of a large social network causing increased voluntary contributions, although these linkages have not previously been tested.

To further examine our measure of social networks, we examine which factors are indicative of larger social networks. It is common for poor neighborhoods to be isolated from more wealthy enclaves. Public policy initiatives often are aimed at removing the real or perceived barriers between rich and poor neighborhoods to improve integration. Such initiatives suggest there are positive externalities from integration among urban residents. We hypothesize that residents of poor neighborhoods who have larger social networks might also have more geographically dispersed networks. It might be that some of the positive externalities that integration proponents hope to achieve might be propagated through these social networks.

We thus have two main hypotheses.

H1: We expect trust and social network size will be positively related to voluntary contribution propensity.

$\mathrm{H} 2$ : We expect that less closed and more geographically dispersed networks will be positively associated with larger social networks.

\section{Methods}

The study utilizes household survey data and a unique social network elicitation tool. These data were collected in field laboratories located in two low-income neighborhoods in Dallas, Texas.

\section{Study Sample}


Study participants were recruited from two different neighborhoods in Dallas, Texas. Neighborhood AA is predominantly African-American and has a population of 33,858 people. Neighborhood $\mathrm{H}$ is largely Hispanic and has a population of 22,789 people. Both neighborhoods are low income with nearly half of all households making less than $\$ 25,000$ per year (Martin et al, 2006(a),(b)). Our data set includes observations from 206 Neighborhood AA participants and 202 Neighborhood H participants.

Table 1 provides demographic information for each of the neighborhoods as well as for the city of Dallas where the neighborhoods are located. The neighborhoods differ from the city, primarily in their ethnic composition and education level. With regards to ethnicity, the neighborhoods are almost mirror images of each other. Neighborhood AA is 69\% African-American and 26\% Hispanic, while Neighborhood $\mathrm{H}$ is $68 \%$ Hispanic and 29\% African-American.

Neighborhoods AA and $\mathrm{H}$ have many similarities. Both neighborhoods are located in the southern sector of Dallas, TX in close proximity to the downtown business district; both share borders with undeveloped land classified as a flood plain; and both possess unique attributes which could potentially make them attractive for development. Additionally, the neighborhoods share the same city services, taxing authorities, and transportation systems. Both neighborhoods are served by numerous non-profit organizations and have a long history of being poor, minority neighborhoods. The primary difference between the two neighborhoods is ethnic.

We chose to focus our study on residents from these two neighborhoods for two main reasons. First, the neighborhoods are economically distressed, and past research suggests that they stand to benefit most from increases in social capital. Second, the 
neighborhoods are ethnically distinct from one another, which allows us to test the degree to which our results are culturally dependent.

Participant recruitment was done by distributing fliers and through face-to-face recruitment in local organizations, parking lots, and residential areas throughout the neighborhoods. Fliers were printed in both English and Spanish and provided a phone number which potential participants could call to register for the study. When they called, participants were registered for a particular session and given directions to the neighborhood laboratory. There were two neighborhood laboratories: one in Neighborhood AA and one in Neighborhood H. All sessions used only participants recruited from the neighborhood in which the session was run.

While care was taken to distribute fliers throughout the neighborhoods, the recruited subject pool was a convenience sample. Hispanics were largely underrepresented in the first recruitment attempt in each neighborhood, so a second wave of recruitment was initiated in order to produce a more ethnically representative sample. ${ }^{3}$ Table 2 describes the composition of each neighborhood sample. For the most part, the composition of participants in our study is similar to that of the community from which they were drawn. However, the two samples did, on average, contain older participants (since we did not recruit anyone under the age of 18) and a larger proportion of participants with a high school education than the neighborhoods from which the samples were drawn.

\section{Data Collection}

\footnotetext{
${ }^{3}$ Recruitment of Hispanics was difficult because many Hispanics in the neighborhoods were either personally or have friend/relatives dealing with immigration status issues. A concerted effort was necessary to build trust in the Hispanic community so that individuals were willing to participate.
} 
Each session had three modules: experimental tasks, the social network task, and the survey. ${ }^{4}$ Each session lasted between 2 and 3 hours. English and Spanish sessions were offered in both neighborhoods; and in every session, participants were offered materials in the language of their choice (English or Spanish). Sessions had between 1 and 17 participants with an average of 9 participants per session. Participants were given a \$20 show-up fee and paid based on their choices for one of the experimental tasks. Average earnings were $\$ 60$ plus the $\$ 20$ show-up fee.

The components of the session of interest to this study are the social network task measuring the size, openness and extend of the social network, and the survey responses measuring trust and giving. The social network task had two parts: a worksheet (adapted from the methodology presented in Johnson 2003) and a questionnaire. The purpose of the worksheet was to assist participants in creating lists of contacts who they can go to for help with various issues: household chores and emotional support, specialized advice (e.g. medical, legal or financial advice), or help finding a job. Participants then used their contact list to answer the questionnaire. The worksheet itself was not collected so that participants could freely identify their contacts without compromising anyone's anonymity. The role of the questionnaire was to translate the information contained within the worksheet into counts for the number of contacts the individual had in various categories and to gather information about the network structure.

Finally, the survey component of the study included questions about household composition, demographics, economic behavior and social behavior. Our measure of

\footnotetext{
${ }^{4}$ The experimental tasks included components for measuring risk preferences (Eckel and Grossman, 2002, 2007), time preferences (Eckel, Johnson and Montmarquette, 2004), laboratory public goods contributions (Ledyard, 1995), and real public goods contributions. The real public goods experiments involved a new extension to public goods experiments which is analyzed in detail in de Oliveira, Croson, and Eckel (2009).
} 
trust stems from responses to the following question found in the World Values Survey: "How much do you trust people from various groups...your family, your neighborhood, people you know personally, people you meet for the first time, people of your own religion, people of another religion, and people of another nationality?" For each group, respondents could rate their level of trust by choosing from four choices: trust completely, trust somewhat, do not trust very much or do not trust at all.

The other key variable obtained from survey data deals with voluntary contribution behavior. Respondents were asked "Have you contributed/volunteered for any nonprofit organization in the past year (include church-related, educational, environmental, social services, international/poverty and others)?" The question was broken into two separate questions, one asking if respondents "contributed" and another asking if respondents "volunteered". Additionally, for the first survey waves in each neighborhood the respondents were also asked to list the organizations to which they contributed/volunteered.

\section{Data}

The primary outcome variables of interest to this study are self-reported charitable voluntary contributions of time or money (CONTRIBUTE) in the past year. We refer to these voluntary contributions as "community contributions." Self-reported voluntary contribution is a binary variable which takes on a value of 1 if any contributions were reported. We chose to include either time or monetary contributions because for some very poor residents monetary contributions might be impossible. By combining the two types of contributions, we believe we more fully represent the willingness of neighborhood residents to impact their communities without discriminating according to 
financial status. Approximately $70 \%$ of the study participants report making community contributions in the past year. In the African American neighborhood 30\% of those contributing only made monetary donations while $12.5 \%$ of those contributing donated time but no money. The remaining 57\% of those donating reported making contributions of both time and money. Similarly in the Hispanic neighborhood, $68 \%$ of individuals who report contributions contributed both time and money. $11.2 \%$ contributed only time and $21 \%$ contributed only money.

The other survey questions which will be analyzed for this study provided information regarding trust, social networks, and demographic data. As previously noted, trust is measured by asking participants if they trust people from various groups. TRUST is then set equal to the total number of different groups a participant trusts completely or somewhat. ${ }^{5}$ On average, this was between 4 and 5 groups, but the variable ranged from 0 to 7 groups.

Social network size (CONTACTS) is the total number of people that can be called upon for help or advice. On average, participants had just under a dozen contacts. CONTACTS was included as both a linear and a quadratic term in order to allow for diminishing impacts as network size increases. ${ }^{6}$ Social network structure was measured in two ways. If participants reported that more than half of the family members and friends in their social network know each other, the network is identified as being closed (CLOSED_NETWORK=1). Likewise, if respondents reported that most of their contacts

\footnotetext{
${ }^{5}$ There are other ways in which the Trust variable might be specified. For instance, one could assign increasing numerical values for the different levels which trust is reported and then sum over these levels for all of the different groups. However, the results reported here are robust to this alternative specification.

${ }^{6}$ CONTACTS_SQ was calculated as (CONTACTS-18) ${ }^{2}$ to avoid high correlation with CONTACTS.
} 
live in the same neighborhood, their network was classified as a neighborhood network (NEIGHBORHOOD=1). Summary data for these variables are presented in Table 4.

It is interesting to note some comparisons across the samples. First, mean contribution frequencies, trust, social network size and social network closure are similar across the two neighborhoods. Of the social capital variables, only the geographic structure of networks differs between the neighborhoods with more neighborhood networks (networks in which most contacts reside in the neighborhood) reported in Neighborhood AA. The key indicator of economic activity in the neighborhoodcurrently searching for work-is slightly higher in Neighborhood AA than in Neighborhood H. Nevertheless, Neighborhood AA has, on average, a more educated population. ${ }^{7}$

\section{Analysis and Results}

Our analysis seeks to answer two primary questions centered on our key hypothesis. First, how do social capital measures of trust and social networks aid in explaining voluntary contributions? Second, what are the indicators of a larger social network--specifically, does engaging individuals outside of the neighborhood community contribute to a larger social network or are their other more important factors?

\section{Social Capital and Self-reported Voluntary Contributions}

Self-reported contributions were analyzed using a probit regression of the binary indicator variable CONTRIBUTE on various social capital and individual characteristics measures. The basic model for the underlying process which generates voluntary contributions, $\mathrm{D}^{*}$ is modeled as

$$
D^{*}=X \beta+S \alpha+\varepsilon .
$$

\footnotetext{
${ }^{7}$ The differences in sample means noted are all statistically significant differences at the 5\% level.
} 
$\mathrm{X}$ contains demographic controls for gender, age, education, religiosity and employment status. $\mathrm{S}$ is the social capital measures for trust and social network size. Applying the probit model then gives

$$
\operatorname{Prob}(\mathrm{D}>\mathrm{D} * \mid \mathrm{X}, \mathrm{S})=\Phi(\mathrm{X} \beta+\mathrm{S} \alpha)
$$

where $\Phi$ is the normal distribution.

The regression results appear in Table 5. We present regressions using our combined sample as well as individually by neighborhoods. Consistent with our first hypothesis, we find that social network size (CONTACTS) is positively related to contribution propensity in both neighborhoods. Table A-1 in the appendix presents the marginal effects from this regression. It demonstrates that an additional contact increases the likelihood of contributing by 1.2 (in Neighborhood AA) or 2.7 (in Neighborhood H) percentage points. It is likely that a larger social network (CONTACTS) increases one's awareness of community needs, likely leading to a higher rate of giving as hypothesized.

The only other variable to have similar results across both neighborhoods is religiosity. The relationship between DEVOUT and voluntary contribution behavior is expected: most religions present a moral code that encourages charitable activity and church giving is included in our measure of voluntary contributions. Churches and the moral code which their members follow, perhaps, transcends neighborhood contexts.

Besides, DEVOUT and CONTACTS, the two neighborhood models (Models 4 and 5), are quite different with regards to the coefficient estimates. In Neighborhood AA, trust is positively related to voluntary contributions and being a minority in the neighborhood decreases contributions. In Neighborhood H, neither trust nor minority status matters. Instead, females in Neighborhood $\mathrm{H}$ report higher rates of voluntary 
contributions. This relationship could be a result of traditional family social structures whereby men are expected to be employed outside the home to provide for the family's financial needs while women are expected to care for the family's social and emotional needs.

Because previous studies have identified trust as an important component of social capital, we decomposed the trust variable and estimated the model replacing the total number of groups an individual trusts with the level of trust in each different group of individuals. Results from this analysis can be found in the appendix in Table A2. In Neighborhood AA, we find that trust in relative strangers impacts giving; including trust in people from your own neighborhood, people of other religions, and people of other nationalities. In contrast, trust in familiars (people you know, people of your own religion, or family members) was not related to the propensity for contributing. In contrast, no measures of trust significantly predicted giving in Neighborhood $\mathrm{H}$.

In summary, this analysis tests our first hypothesis that trust and social network size would be positively related to voluntary contribution behavior. We find mixed results. Social network size matters for contribution behavior in both neighborhoods, but the results for trust vary by neighborhood.

\section{Determinants of Social Network Size}

Since social network size is positively related to contribution behavior in both neighborhoods, our second hypothesis explores the determinants of an individual's social network size. The regressions in Table 6 estimate the determinants of social network size (CONTACTS). Again, we first look at the combined sample and subsequently the two neighborhoods separately. 
We find mixed support for our second hypothesis. In both neighborhoods individuals with more than half of their contacts residing outside of the neighborhood have a significantly larger social network. This supports our second hypothesis. However, measures of the openness of the network significantly predict network size only in Neighborhood $\mathrm{H}$ and not in Neighborhood AA. And opposite of our prediction, more closed networks in Neighborhood $\mathrm{H}$ are larger rather than smaller.

Turning now to our other measure of social capital, we note that trust initially appears to matter only in Neighborhood H. However, when trust is decomposed, we find that trust in people you know actually matters for both neighborhoods. Further, this is the only group of people for which the level of trust matters for network size. The results for the decomposition of trust can be found in Table A-3.

In summary, we find limited support for hypothesis two. Having contacts outside of the neighborhood is positively related to social network size, but the network's openness is not.

\section{Discussion}

Many of the results for both voluntary contribution behavior and social network size are different in each neighborhood. However, for policy prescription it is most helpful to focus on results that are robust across neighborhoods. We expected to find differences across the two ethnic groups (African-American and Hispanic) that would drive neighborhood differences, but this is not the case. Ethnicity in and of itself does not seem to matter.

We hypothesized that social network size (CONTACTS) and levels of trust (TRUST) would be positively related to voluntary contribution rates. In every model 
specification, we find that individuals with a large social network are more likely to contribute. Additionally, individuals who attend religious services at least weekly are more likely to contribute to the neighborhood. This is understandable since many of the community organizations in the neighborhood are church-affiliated. However, the results for TRUST are less robust. We expected TRUST to be positively related to voluntary contribution rates and when one looks at the composite neighborhood sample (Models 1-3) this result holds. However, we discover that the model for voluntary contributions is different in each of the neighborhoods when analyzed separately. When we allow for these differences, trust only matters for Neighborhood AA.

We hypothesized that network closure (CLOSED_NETWORK) and geographic dispersion (NEIGHBORHOOD_NETWORK) would be positively related to network size. Our results support the latter contention in both neighborhoods, which provides some measure of support for initiatives aimed at integrating urban residents from different neighborhoods. However, network closure is only positively related to network size in Neighborhood H.

All studies have limitations, and ours is no exception. First, data on the size of the voluntary contributions made by neighborhood residents was unavailable. Clearly, more sizeable contributions are likely to have a more profound impact on the neighborhood and future research should attempt to measure the determinant of both contribution propensity and voluntary contribution size. Second, we found many results that only hold in one neighborhood, but not the other. Extending the sample to other neighborhoods would provide valuable insight as to when a particular result is most likely to hold. As it stand with only two neighborhoods for comparison, it is difficult to 
understand whether a particular neighborhood should be considered as the norm or an outlier.

Our results suggest that increasing network size and levels of religiosity will increase voluntary contribution rates. DEVOUT is significant in both neighborhoods and does not appear to operate through network formation. Additionally, religiosity is powerful; the marginal effect is a 16-percentage point increase in the probability of contributing! However, government cannot necessarily meaningfully impact religiosity directly. An alternative policy initiative might focus on increasing support for faithbased charitable initiatives, especially in low-income neighborhoods. Support might take the form of tax credits, matching grants, or other financial incentives. This type of policy doesn't promote religious attendance directly, but it does increase the activity of religious organizations and our results clearly suggest that religious organizations have influence in the communities.

CONTACTS is also significantly related to contribution in both neighborhoods and is positively impacted by the number of people individuals know outside of the neighborhood. Thus encouraging neighborhood members to make additional extraneighborhood contacts may increase social network size with resulting increased contributions. One means of pursuing this type of policy initiative is to work towards making low-income neighborhoods a more desirable place for outsiders to engage. This should bring benefits to residents through increased contacts and increased local community participation.

\section{Conclusions}


Our objective was to examine the role of social capital in influencing the voluntary provision of local public goods. Our study is the first to analyze the impact of social capital in the form of both social networks and trust on real voluntary community contributions in poor neighborhoods. We find that social networks and trust impact voluntary contribution behavior differently. While social network size increases contribution propensity robustly across the two neighborhoods, the results for trust are contextually dependent.

The key results center on a means for increasing voluntary contributions by increasing network size that is facilitated by encouraging the formation of extraneighborhood social networks. Additionally, religiosity is a powerful driving force for increased donation propensity in both neighborhoods and this provides some support for encouraging faith based charitable initiatives in low-income communities

We conclude that policy makers should recognize the social environment when making policy prescriptions rather than analyzing summary demographic information alone. For example, ethnicity had no role in explaining charitable contributions or social network size across the two neighborhoods. As a whole, the results point to a greater need for economists to recognize the complex social relationships in which economic activities occur and to measure the impact of these relationships in explaining and predicting outcomes and forming policy prescriptions. 


\section{References}

Adelman, I. and C.T. Morris. 1967. Society, Politics and Economics.

Anderson, Lisa R., Jennifer M. Mellor, and Jeffrey Milyo. 2004. Social Capital and Contributions in a Public-Goods Experiment. American Economic Review. 94(2): 373-376.

Beugelsdijk, S. and T. van Schaik. 2001. Social Capital and Regional Economic Growth. Mimeo, Tillburg Universtiy.

Bowles, S. and H. Gintis. 2002. Social Capital and Community Governance. The Economic Journal. 112(I): 419-436.

Camerer, Colin. 2003. Behavioral Game Theory: Experiments in Strategic Interaction. Russell Sage Foundation, Princeton University Press: New York, NY.

DiPasquale, D. and E. Glaeser. 1999. Incentives and social capital: do homeowners make better citizens? Journal of Urban Economics. 45: 354-84.

Eckel, C. C., C. A. Johnson and C. Montmarquette. 2004. "Saving decisions of the working poor: short- and long-term horizons." Research in Experimental Economics, Volume 10: Field Experiments in Economics, edited by Jeff Carpenter, Glenn W. Harrison, and John A. List, (Greenwich, CT: JAI Press): p. 219-260.

Eckel, Catherine \& Philip J. Grossman. 2002. "Sex Differences and Statistical Stereotyping in Attitudes Toward Financial Risk." Evolution and Human Behavior 23(4): 281-295.

Eckel, Catherine \& Philip J. Grossman. 2007. "Forecasting Risk Attitudes: An Experimental Study Using Actual and Forecast Gamble Choices." Forthcoming, Journal of Economic Behavior and Organization.

Freeman, Richard B. 1997. "Working for Nothing: The Supply of Volunteer Labor." Journal of Labor Economics. 15.1 Part 2: p. S140-S166.

Frey, Bruno S. and Alois Stutzer. 2007. Economics and Psychology: A Promising New Cross-Disciplinary Field. MIT Press: Cambridge MA.

Glaeser, E. L., David I. Laibson, Jose A. Scheinkman, and Christine L. Soutter. 2000. Measuring Trust. Quarterly Journal of Economics. 115(3): 811-846

Grootaert, Christiaan. 1999. Social Capital, Household Welfare and Poverty in Indonesia. World Bank Working Paper, unpublished

Helliwell, J. and R. Putnam. 1995. Economic Growth and Social Capital in Italy. Eastern Economic Journal, 21(3): 295-307. 
Johnson, Cathleen. 2003. A Model of Social Capital Formation. SRDC Working Paper Series 03-01.

Knack, S. 1999. Social Capital, Growth and Poverty: A Survey and Extensions. Social Capital Initiative Working Paper No.7. Washington, D.C.: The World Bank.

Knack, S. and P. Keefer. 1997. Does Social Capital Have an Economic Payoff? A Cross-Country Investigation. Quarterly Journal of Economics, 52(4): 12511287.

Ledyard, J., 1995, Public goods: A survey of experimental research, in: John Kagel and Alvin Roth, eds., The handbook of experimental economics. (Princeton University Pre , Princeton, N J).

Martin, Marcus, Timothy Bray, Julie Kibler, Megan Thibos, Teri Wesson, and Justine Hines. 2006(a). South Dallas Research Compilation. J. McDonald Williams Institute Research Brief.

Martin, Marcus, Timothy Bray, Julie Kibler, Megan Thibos, Teri Wesson, and Rachael Jackson. 2006(b). West Dallas Research Compilation. J. McDonald Williams Institute Research Brief.

McAdam, Doug and Ronnelle Paulsen. 1993. Specifying the Relationship Between Social Ties and Activism. The American Journal of Sociology. 99.3: 640-667.

Miguel, E., P. Gertler and D.I. Levine, DI. 2003. Did Industrialization Destroy Social Capital in Indonesia? Center for International and Development Economics Research, Working Paper No. C03-131, Berkeley, CA.

Musick, Marc A., John Wilson and William B. Bynum, Jr. 2000. "Race and Formal Volunteering: The Differential Effects of Class and Religion." Social Forces. 78.4: 1539-1570.

Oliveira, A., R. Croson, and C. Eckel. 2009. Are Preferences Stable Across Domains? An Experimental Investigation of Social Preferences in the Field. CBEES Working Paper No. 2008-3.

Olken, Benjamin A. 2006. Do Television and Radio Destroy Social Capital? Evidence from Indonesian Villages, NBER Working Papers 12561, National Bureau of Economic Research, Inc.

Putnam, R.D. 1995. Tuning In, Tuning Out: The Strange Disappearance of Social Capital in America. PS: Political Science and Politics. 28(4): 664-683.

Putnam, R.D., R. Leonardi and N.Y. Raffaella. 1993. Making Democracy Work: Civic Traditions in Modern Italy. Princeton: Princeton University Press.

Quillian, Lincoln and Rozlyn Redd. 2006. Can Social Capital Explain Persistant Racial Poverty Gaps. National Poverty Center Working Papers Series \#06-12. 
Rodrik, D. 1999. Where Did All the Growth Go? External Shocks, Social Conflict, and Growth Collapses. Journal of Economic Growth. 4(4): 385 - 412.

Rose, R. 1999. Getting Things Done in an Anti-Modern Society: Social Capital Networks in Russia. in Social Capital, A Multifaceted Perspective (Dasgupta, P. and I. Serageldin, eds.). Washington D.C., The World Bank..

Sampson, R. J., S.W. Raudenbush and F. Earls. 1997. Neighborhoods and violent crime: a multilevel study of collective efficacy. Science. 277: 918-924.

Temple, J. 1998. Initial Conditions, Social Capital, and Growth in Africa. Journal of African Economies. 7(3): 309-347.

Temple, J. and P. Johnson. 1998. Social Capability and Economic Growth. Quarterly Journal of Economics. 965-990.

Whiteley, P. 2000. Economic Growth and Social Capital. Political Studies. 48: 443.

Yunus, M. 2008. Social Business is the Solution. Address to the Lindau Meeting of Nobel Laureates in Economic Sciences, August 21, 2008.

Zak, P.A. and S. Knack. Trust and Growth. The Economic Journal. 111: 295-321. 
Table 1. Neighborhood Demographics

\begin{tabular}{|l|c|c|c|}
\hline & City of Dallas & Neighborhood AA & Neighborhood H \\
\hline Population & 1223584 & 33858 & 22789 \\
\hline \% Hispanic & $42 \%$ & $26 \%$ & $68 \%$ \\
\hline$\%$ African-American & $24 \%$ & $69 \%$ & $29 \%$ \\
\hline$\%$ White or other & $34 \%$ & $5 \%$ & $3 \%$ \\
\hline Median Age & 32 & 32 & 25.6 \\
\hline High School Education & N/A & $47 \%$ & $35 \%$ \\
\hline$\%$ Male & $51 \%$ & $49 \%$ & $50 \%$ \\
\hline$\%$ Female & $49 \%$ & $51 \%$ & $50 \%$ \\
\hline
\end{tabular}

Source: Martin et al, 2006 (a), (b)

Table 2. Sample Demographics

\begin{tabular}{|l|c|c|c|c|}
\hline & Neighborhood AA & $\begin{array}{c}\text { Sample AA } \\
(\mathbf{N = 2 0 6})\end{array}$ & Neighborhood H & Sample H(N=202) \\
\hline Population & 33858 & 206 & 22789 & 202 \\
\hline \% Hispanic & $26 \%$ & $18 \%$ & $68 \%$ & $66 \%$ \\
\hline \% African-American & $69 \%$ & $82 \%$ & $29 \%$ & $34 \%$ \\
\hline \% White or other & $5 \%$ & $0 \%$ & $3 \%$ & $0 \%$ \\
\hline Median Age & 32 & 39 & 25.6 & 41 \\
\hline High School Education & $47 \%$ & $65 \%$ & $35 \%$ & $45 \%$ \\
\hline$\%$ Male & $49 \%$ & $40 \%$ & $50 \%$ & $38 \%$ \\
\hline \% Female & $51 \%$ & $60 \%$ & $50 \%$ & $62 \%$ \\
\hline
\end{tabular}


Table 3. Variable Descriptions

\begin{tabular}{|c|c|}
\hline Variable & Description \\
\hline CONTRIBUTE & $\begin{array}{l}\text { Voluntary contributions indicator variable; } 1 \text { indicates contributions of time or money to } \\
\text { nonprofit organization(s) in the past year }\end{array}$ \\
\hline CONTACTS & total number of contacts which can be relied upon for help or advice \\
\hline CONTACTS_SQ & $(\mathrm{CONTACTS}-18)^{\wedge} 2$ \\
\hline TRUST & $\begin{array}{l}\text { total number of groups of others who are trusted; "others" includes people you know, } \\
\text { people you meet for the first time, people of your religion, people of other religions, } \\
\text { people of a different nationality, family members, other neighborhood residents }\end{array}$ \\
\hline CLOSED_NETWORK & $\begin{array}{l}\text { network closure indicator variable; } 1 \text { indicates that more than half of your family and } \\
\text { friend contacts know each other }\end{array}$ \\
\hline NEIGHBORHOOD_NETWORK & $\begin{array}{l}\text { neighborhood network indicator variable; } 1 \text { indicates that more than half of your contacts } \\
\text { live in the same neighborhood as you }\end{array}$ \\
\hline MINORITY & $\begin{array}{l}\text { indicates ethnic status is a minority in the neighborhood; } 1 \text { indicates Hispanics in } \\
\text { Neighborhood AA and African Americans in Neighborhood H }\end{array}$ \\
\hline AA_MINORITY & indicates participant is a minority (Hispanic) in Neighborhood AA \\
\hline H_MINORITY & indicates participant is a minority (African American) in Neighborhood $\mathrm{H}$ \\
\hline FEMALE & participant is female \\
\hline DEVOUT & participant attends religious services at least once per week \\
\hline EDUCATED & participant has a high school education or greater \\
\hline AGE & participant's age \\
\hline KIDS & number of children under 18 living in the participants household \\
\hline NEEDS_WORK & participant is actively seeking employment \\
\hline
\end{tabular}


Table 4. Variable Summary Statistics

\begin{tabular}{|l|c|c|c|c|c|c|c|c|}
\hline & \multicolumn{3}{|c|}{ Neighborhood AA (N=206) } & \multicolumn{4}{c|}{ Neighborhood H (N=202) } \\
\hline & Mean & Std. Dev & Min & Max & Mean & Std. Dev & Min & Max \\
\hline CONTRIBUTE & 0.694 & 0.462 & 0 & 1 & 0.708 & 0.456 & 0 & 1 \\
\hline CONTACTS & 11.917 & 9.321 & 0 & 75 & 11.178 & 5.356 & 1 & 34 \\
\hline CONTACTS_SQ & 123.461 & 263.323 & 0 & 3249 & 75.079 & 66.391 & 0 & 289 \\
\hline TRUST & 4.733 & 1.978 & 0 & 7 & 4.554 & 1.765 & 0 & 7 \\
\hline CLOSED_NETWORK & 0.854 & 0.354 & 0 & 1 & 0.827 & 0.379 & 0 & 1 \\
\hline NEIGHBORHOOD_NETWORK & 0.631 & 0.484 & 0 & 1 & 0.490 & 0.501 & 0 & 1 \\
\hline MINORITY & 0.175 & 0.381 & 0 & 1 & 0.342 & 0.475 & 0 & 1 \\
\hline FEMALE & 0.617 & 0.487 & 0 & 1 & 0.619 & 0.487 & 0 & 1 \\
\hline DEVOUT & 0.481 & 0.501 & 0 & 1 & 0.480 & 0.501 & 0 & 1 \\
\hline EDUCATED & 0.636 & 0.482 & 0 & 1 & 0.455 & 0.499 & 0 & 1 \\
\hline AGE & 38.636 & 12.474 & 18 & 64 & 39.876 & 15.950 & 18 & 86 \\
\hline KIDS & 1.437 & 1.388 & 0 & 7 & 1.718 & 1.628 & 0 & 9 \\
\hline NEEDS_WORK & 0.301 & 0.460 & 0 & 1 & 0.262 & 0.441 & 0 & 1 \\
\hline
\end{tabular}


Table 5. Models of Voluntary Contribution Behavior

Dependent variable is CONTRIBUTE.

\begin{tabular}{|c|c|c|c|c|c|}
\hline & & mposite San & & Neighborhood AA & Neighborhood $\mathrm{H}$ \\
\hline & Model 1 & Model 2 & Model 3 & Model 4 & Model 5 \\
\hline CONTACTS & $0.0314 * *$ & $0.0282 *$ & $0.0289 *$ & $0.0392 *$ & $0.0932 *$ \\
\hline & $(0.0112)$ & $(0.0113)$ & $(0.0112)$ & $(0.0171)$ & $(0.0462)$ \\
\hline CONTACTS_SQ & $-0.0013 * *$ & $-0.0013^{*}$ & $-0.0013 * *$ & -0.0023 & 0.0052 \\
\hline & $(0.0005)$ & $(0.0005)$ & $(0.0005)$ & $(0.0012)$ & $(0.0031)$ \\
\hline TRUST & $0.1186 * *$ & $0.1213 * *$ & $0.1123 * *$ & $0.1829 * *$ & 0.0470 \\
\hline & $(0.0404)$ & $(0.0397)$ & $(0.0403)$ & $(0.0583)$ & $(0.0614)$ \\
\hline HISPANIC & $\begin{array}{l}-0.1131 \\
(0.1623)\end{array}$ & & & & \\
\hline MINORITY & & $\begin{array}{c}-0.3361 * \\
(0.1593)\end{array}$ & & $\begin{array}{l}-0.6800 * \\
(0.3303)\end{array}$ & $\begin{array}{l}-0.0361 \\
(0.2345)\end{array}$ \\
\hline AA_MINORITY & & & $\begin{array}{c}-0.6173^{*} \\
(0.2517)\end{array}$ & & \\
\hline H_MINORITY & & & $\begin{array}{l}-0.1880 \\
(0.1906)\end{array}$ & & \\
\hline FEMALE & $\begin{array}{l}0.3507 * \\
(0.1446)\end{array}$ & $\begin{array}{l}0.3731 * \\
(0.1449)\end{array}$ & $\begin{array}{l}0.3648^{*} \\
(0.1451)\end{array}$ & $\begin{array}{c}0.2562 \\
(0.2141)\end{array}$ & $\begin{array}{l}0.4811^{*} \\
(0.2090)\end{array}$ \\
\hline DEVOUT & $\begin{array}{c}0.5844 * * * \\
(0.1454)\end{array}$ & $\begin{array}{c}0.6032 * * * \\
(0.1462)\end{array}$ & $\begin{array}{c}0.6035^{* * *} * \\
(0.1465)\end{array}$ & $\begin{array}{c}0.6700 * * \\
(0.2243)\end{array}$ & $\begin{array}{c}0.6830 * * * \\
(0.2073)\end{array}$ \\
\hline EDUCATED & $\begin{array}{c}0.2225 \\
(0.1564)\end{array}$ & $\begin{array}{c}0.2588 \\
(0.1438)\end{array}$ & $\begin{array}{c}0.1986 \\
(0.1499)\end{array}$ & $\begin{array}{c}0.1020 \\
(0.2505)\end{array}$ & $\begin{array}{c}0.1817 \\
(0.2206)\end{array}$ \\
\hline AGE & $\begin{array}{l}0.0127^{*} \\
(0.0060)\end{array}$ & $\begin{array}{l}0.0120^{*} \\
(0.0061)\end{array}$ & $\begin{array}{c}0.0111 \\
(0.0061)\end{array}$ & $\begin{array}{c}0.0146 \\
(0.0106)\end{array}$ & $\begin{array}{c}0.0081 \\
(0.0078)\end{array}$ \\
\hline KIDS & $\begin{array}{c}-0.0374 \\
(0.0495)\end{array}$ & $\begin{array}{l}-0.0239 \\
(0.0502)\end{array}$ & $\begin{array}{l}-0.0232 \\
(0.0504)\end{array}$ & $\begin{array}{c}0.0567 \\
(0.0862)\end{array}$ & $\begin{array}{c}-0.0784 \\
(0.0663)\end{array}$ \\
\hline NEEDS_WORK & $\begin{array}{l}-0.1017 \\
(0.1556)\end{array}$ & $\begin{array}{l}-0.0887 \\
(0.1540)\end{array}$ & $\begin{array}{l}-0.1160 \\
(0.1552)\end{array}$ & $\begin{array}{c}0.0514 \\
(0.2326)\end{array}$ & $\begin{array}{l}-0.3150 \\
(0.2239)\end{array}$ \\
\hline Constant & $\begin{array}{c}-1.1427 * * \\
(0.3890)\end{array}$ & $\begin{array}{c}-1.1167 * * \\
(0.3709)\end{array}$ & $\begin{array}{c}-1.0054 * * \\
(0.3774)\end{array}$ & $\begin{array}{c}-1.4954 * \\
(0.6483)\end{array}$ & $\begin{array}{c}-1.7928 * \\
(0.8677)\end{array}$ \\
\hline $\mathbf{N}$ & 408 & 408 & 408 & 206 & 202 \\
\hline Pseudo R sq & 0.1353 & 0.1432 & 0.1474 & 0.2294 & 0.1238 \\
\hline
\end{tabular}

Standard errors in parentheses

$* \mathrm{p}<0.05 * * \mathrm{p}<0.01 * * * \mathrm{p}<0.001$ 
Table 6. Determinants of Network Size

Dependent variable is CONTACTS.

\begin{tabular}{|c|c|c|c|}
\hline & $\begin{array}{c}\text { Composite Sample } \\
\text { Mode } 6\end{array}$ & $\begin{array}{c}\text { Neighborhood AA } \\
\text { Model } 7\end{array}$ & $\begin{array}{l}\text { Neighborhood } \mathrm{H} \\
\text { Model } 8\end{array}$ \\
\hline TRUST & $0.4267 *$ & 0.3906 & $0.5277 *$ \\
\hline & $(0.2044)$ & $(0.3454)$ & $(0.2090)$ \\
\hline CLOSED_NETWORK & 1.4265 & -0.6171 & $2.1189^{*}$ \\
\hline NEIGHBORHOOD_NETWORK & $\begin{array}{c}-4.1783 * * * \\
(0.7397)\end{array}$ & $\begin{array}{l}-6.2889 * * * \\
(1.2874)\end{array}$ & $\begin{array}{l}-2.2969^{* *} \\
(0.7418)\end{array}$ \\
\hline MINORITY & & $\begin{array}{l}-1.0377 \\
(2.0179)\end{array}$ & $\begin{array}{c}-3.4501 * * * \\
(0.8103)\end{array}$ \\
\hline AA_MINORITY & $\begin{array}{l}-1.4363 \\
(1.3540)\end{array}$ & & \\
\hline H_MINORITY & $\begin{array}{c}-3.7131 * * * \\
(0.9801)\end{array}$ & & \\
\hline FEMALE & $\begin{array}{c}0.0385 \\
(0.7476)\end{array}$ & $\begin{array}{c}0.4082 \\
(1.2602)\end{array}$ & $\begin{array}{l}-0.2779 \\
(0.7528)\end{array}$ \\
\hline DEVOUT & $\begin{array}{l}-0.8134 \\
(0.7335)\end{array}$ & $\begin{array}{l}-2.4039 \\
(1.2804)\end{array}$ & $\begin{array}{c}0.4125 \\
(0.7186)\end{array}$ \\
\hline EDUCATED & $\begin{array}{c}1.3931 \\
(0.7618)\end{array}$ & $\begin{array}{c}2.5430 \\
(1.4705)\end{array}$ & $\begin{array}{c}0.6642 \\
(0.7780)\end{array}$ \\
\hline AGE & $\begin{array}{c}-0.0861 * * \\
(0.0287)\end{array}$ & $\begin{array}{l}-0.0950 \\
(0.0559)\end{array}$ & $\begin{array}{c}-0.0835 * * \\
(0.0258)\end{array}$ \\
\hline KIDS & $\begin{array}{c}0.2591 \\
(0.2569)\end{array}$ & $\begin{array}{c}0.1013 \\
(0.4821)\end{array}$ & $\begin{array}{c}0.2860 \\
(0.2377)\end{array}$ \\
\hline NEEDS_WORK & $\begin{array}{l}-0.8505 \\
(0.8152)\end{array}$ & $\begin{array}{l}-2.1545 \\
(1.3913)\end{array}$ & $\begin{array}{c}0.3814 \\
(0.8186)\end{array}$ \\
\hline Constant & $\begin{array}{c}14.2872 * * * \\
(1.9345)\end{array}$ & $\begin{array}{c}18.2059 * * * \\
(3.5341)\end{array}$ & $\begin{array}{c}11.7354 * * * \\
(1.8300)\end{array}$ \\
\hline $\mathbf{N}$ & 408 & 206 & 202 \\
\hline R-sq & 0.1437 & 0.1779 & 0.1942 \\
\hline
\end{tabular}

Standard errors in parentheses

$* \mathrm{p}<0.05 * * \mathrm{p}<0.01 * * * \mathrm{p}<0.001$ 


\section{Appendix A}

\section{Marginal Effects for Probit Models}

In all cases, marginal effects are calculated at the sample average for each variable and reported in Table A-1.

For the case of binary variables (TRUST, MINORITY, FEMALE, DEVOUT, EDUCATED, NEEDS_WORK), marginal effects are calculated as the difference between the probabilities that result when the variable takes its two different values with the other variables held at their sample means.

For the case of discrete variables (CONTACTS, AGE, and KIDS), marginal effects are calculated as the difference between the probabilities that result when the variable is increased by one (i.e. one additional contact, year, or child) above its sample mean with the other variables held at their sample means.

\section{Table A-1. Marginal Effects for Models 4 and 5}

Dependent variable is CONTRIBUTE.

\begin{tabular}{|lc|c|}
\hline & $\begin{array}{c}\text { Neighborhood AA } \\
\text { Model 4 } \\
\text { (Marginal Effects) }\end{array}$ & $\begin{array}{c}\text { Neighborhood H } \\
\text { Model 5 } \\
\text { (Marginal Effects) }\end{array}$ \\
CONTACTS & $0.0125^{*}$ & $0.0273^{*}$ \\
CONTACTS_SQ & -0.0006 & 0.0156 \\
TRUST & $0.0556^{* *}$ & 0.0150 \\
MINORITY & $-0.0491^{*}$ & -0.0931 \\
FEMALE & 0.1787 & $0.1955^{*}$ \\
DEVOUT & $0.1627^{*}$ & $0.1618^{* * *}$ \\
EDUCATED & 0.1692 & 0.1310 \\
AGE & 0.0047 & 0.0026 \\
KIDS & 0.0182 & -0.0255 \\
NEEDS_WORK & 0.0887 & -0.0716 \\
\hline
\end{tabular}

$* \mathrm{p}<0.05 * * \mathrm{p}<0.01 * * * \mathrm{p}<0.001$ 


\section{Decomposing Trust}

Tables A-2 and A-3 presents the coefficient estimates for the various trust variables that result when the models are re-estimated, replacing TRUST with each of the individual components that make up the TRUST variable. The results in Table A-2 represent seven new regressions run for each neighborhood when trust is decomposed for Model 4 (Neighborhood AA) and Model 5 (Neighborhood H). The results in Table A-3 are from seven new regressions run for each neighborhood when trust is decomposed for Model 7 (Neighborhood AA) and Model 8 (Neighborhood H).

Table A-2 Trust Decomposition for The Models of Voluntary Contributions Dependent variable is CONTRIBUTE.

\begin{tabular}{|l|c|c|}
\hline & $\begin{array}{c}\text { Neighborhood } \\
\text { AA }\end{array}$ & $\begin{array}{c}\text { Neighborhood } \\
\text { H }\end{array}$ \\
\hline Trust in people in your family & 0.2110 & 0.0444 \\
\hline Trust in people from your neighborhood & $0.5077 *$ & 0.0335 \\
\hline Trust in people you know personally & 0.0917 & -0.0112 \\
\hline Trust in people you meet for the first time & 0.3858 & 0.0571 \\
\hline Trust in people of your own religion & 0.3762 & 0.3616 \\
\hline Trust in people of another religion & $0.6550^{* *}$ & 0.0656 \\
\hline Trust in people of another nationality & $0.6601 * *$ & 0.2781 \\
\hline
\end{tabular}

$* \mathrm{p}<0.05 * * \mathrm{p}<0.01 * * * \mathrm{p}<0.001$

Table A-3 Trust Decomposition for The Determinants of Network Size Dependent Variable is CONTACTS

\begin{tabular}{|l|c|c|}
\hline & $\begin{array}{c}\text { Neighborhood } \\
\text { AA }\end{array}$ & $\begin{array}{c}\text { Neighborhood } \\
\text { H }\end{array}$ \\
\hline Trust in people in your family & 4.135 & 2.314 \\
\hline Trust in people from your neighborhood & 2.283 & 1.503 \\
\hline Trust in people you know personally & $4.581^{*}$ & $2.806^{* *}$ \\
\hline Trust in people you meet for the first time & 0.1757 & 0.3955 \\
\hline Trust in people of your own religion & 0.4362 & 1.324 \\
\hline Trust in people of another religion & -0.7364 & 0.3216 \\
\hline Trust in people of another nationality & -1.491 & 1.067 \\
\hline
\end{tabular}

$* \mathrm{p}<0.05 * * \mathrm{p}<0.01 * * * \mathrm{p}<0.001$ 